\title{
A simple chemical approach to regenerating the strength of thermally damaged glass fibre
}

\section{S.T. Bashir}

L. Yang ${ }^{\mathrm{a}, *}$

l.yang@strath.ac.uk

R. Anderson

P.L. Tang

J.J. Liggat

J.L. Thomason

âniversity of Strathclyde, Department of Mechanical and Aerospace Engineering, 75 Montrose Street, Glasgow G1 1XJ, United Kingdom

bAgilent Technologies, Mobile Measurement Group, Edinburgh EH12 9DJ, United Kingdom

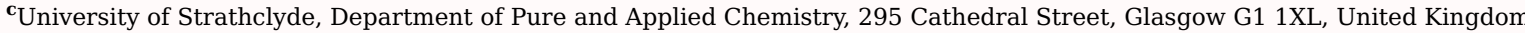

*Corresponding author

Abstract

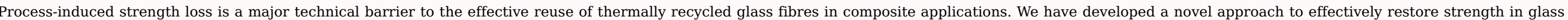

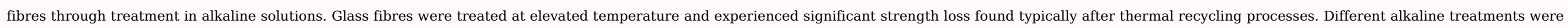

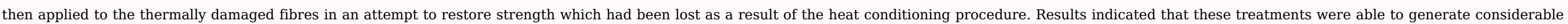

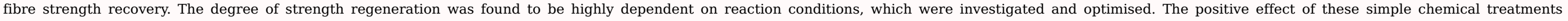
demonstrated great potential for facilitating the reuse of thermally recycled glass fibres in composite applications.

Keywords: A. Glass fibres; A. Recycling; B. Strength; E. Surface treatments

\section{Introduction}

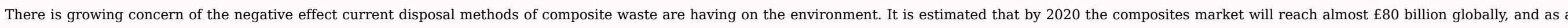

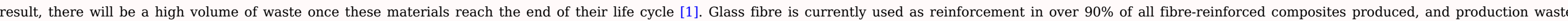

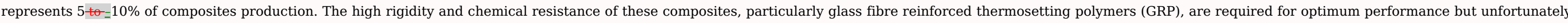

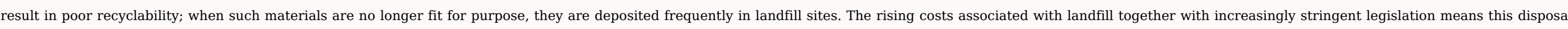

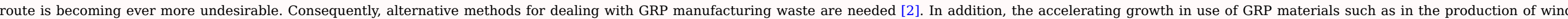
turbine blades [3] means it is imperative that a long-term, cost-effective, recycling solution be developed for end-of-life composites.

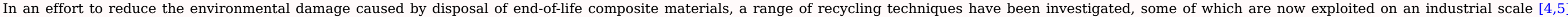

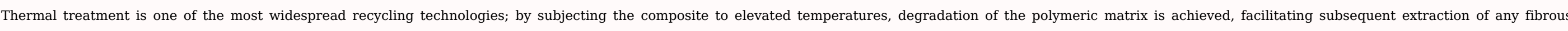

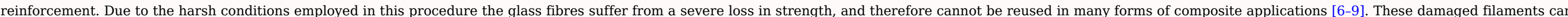




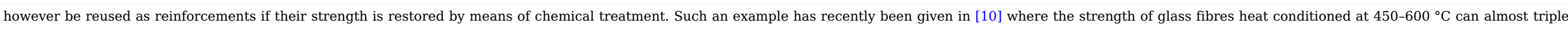

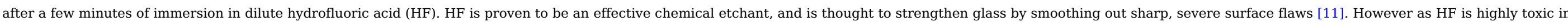

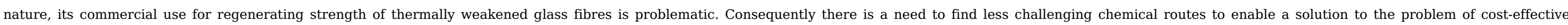
recycling and reuse of the glass fibres in GRP waste.

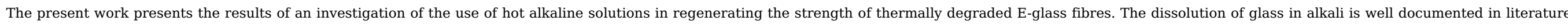

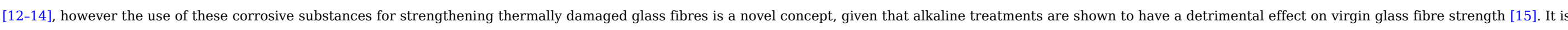

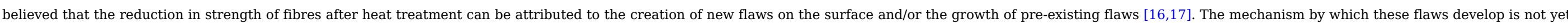

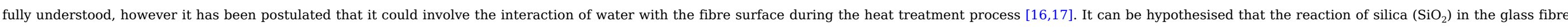

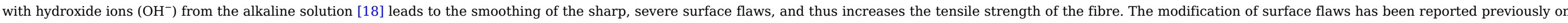
bulk glass with $\mathrm{HF}$ as the corrosive medium [11].

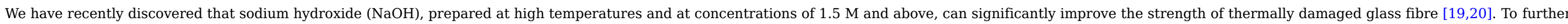

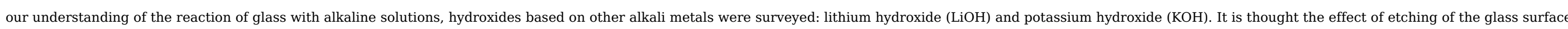

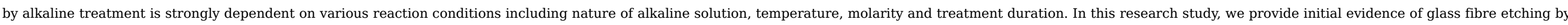

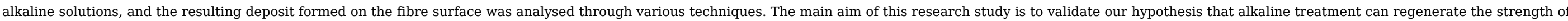

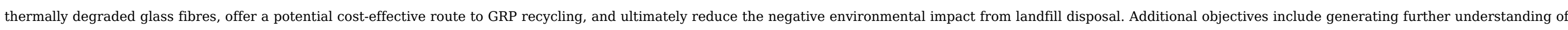
the etching mechanism and how differences in chemical properties of alkali metal hydroxides affect their reaction with glass fibre.

\section{Experimental}

\subsection{Materials}

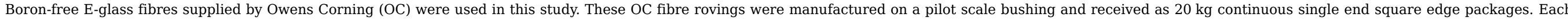

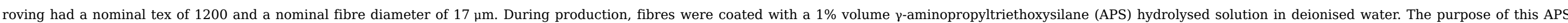

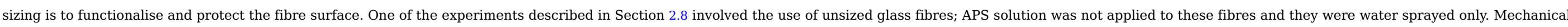

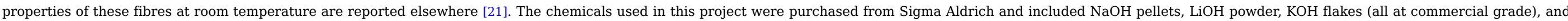
standard $37 \%$ concentrated hydrochloric acid $(\mathrm{HCl})$

\subsection{Thermal treatment}

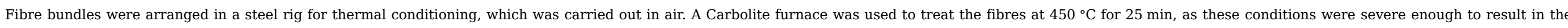

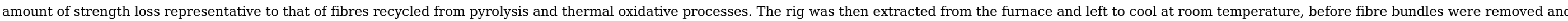
treated in various alkaline solutions. Further details of the heat conditioning procedure are given in $[6,7]$.

\subsection{Alkaline treatment}

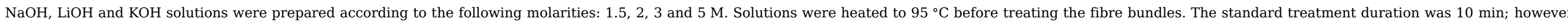

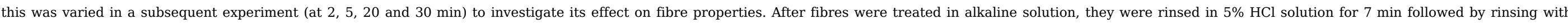

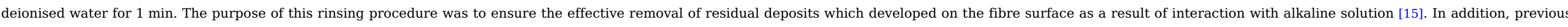

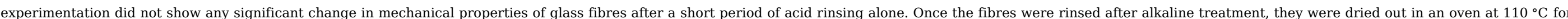
$15 \mathrm{~min}$.

\subsection{Single fibre tensile testing}




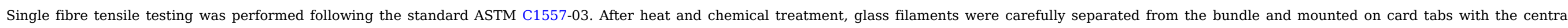

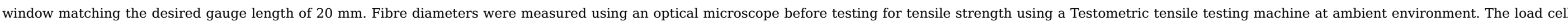

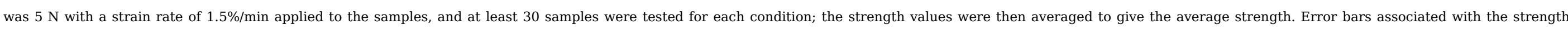
measurements represent $95 \%$ confidence limits. The tensile test procedure is described in detail elsewhere [21].

\subsection{Scanning electron microscopy (SEM)}

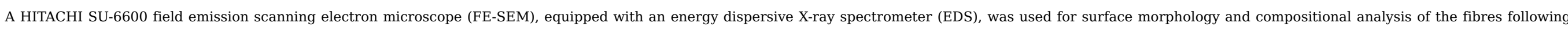

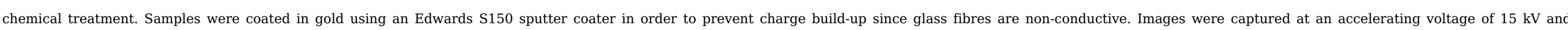
extraction voltage of $1.8 \mathrm{kV}$

\subsection{Atomic force microscopy (AFM)}

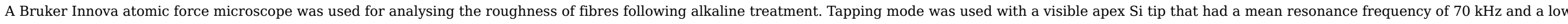

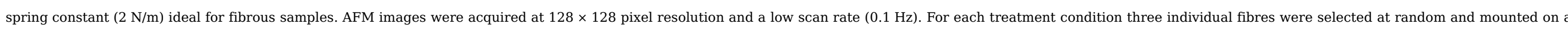

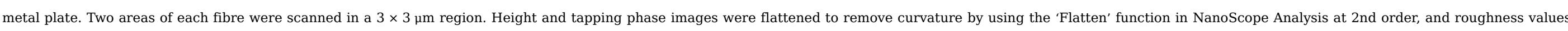
were measured and plotted as a function of treatment time.

\subsection{Fourier transform infrared spectroscopy (FT-IR)}

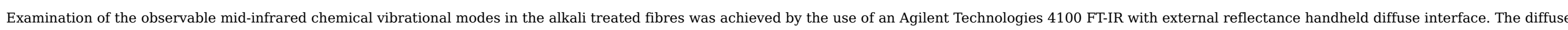

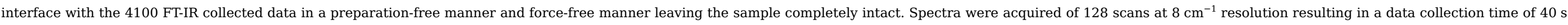

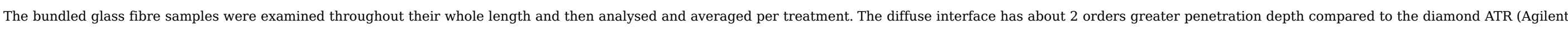
Technologies 4500) and less bias towards the fingerprint region, and is therefore more representative of the sample as well as containing greater data density.

\subsection{Mass loss and diameter reduction of fibres after alkaline treatment}

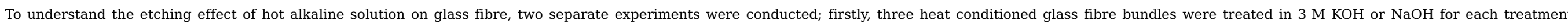

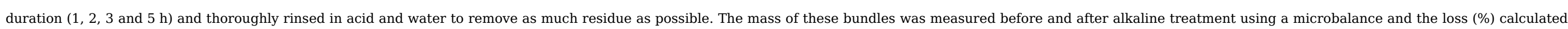

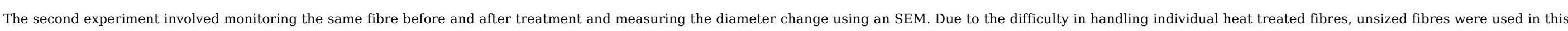

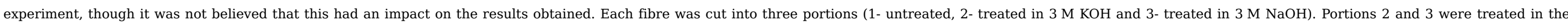

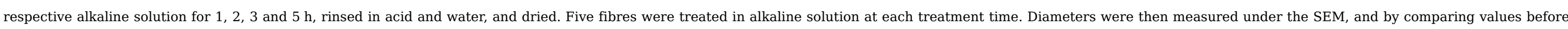
and after treatment, the fibre diameter reduction (\%) was determined. The error bars used for mass loss and diameter reduction measurements show the standard deviation.

\section{Results and discussion}

\subsection{Strength regeneration by alkaline treatment}

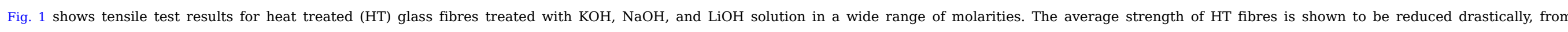

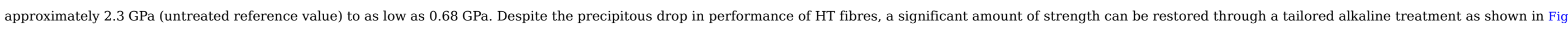

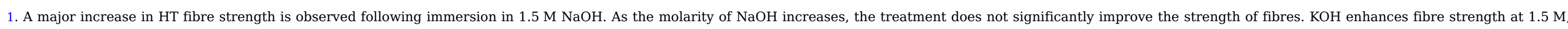

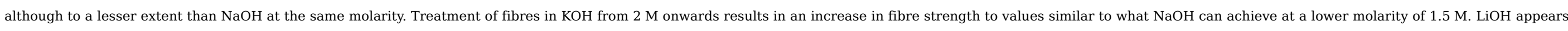
to have little effect on HT fibre properties for the molarity range investigated. 


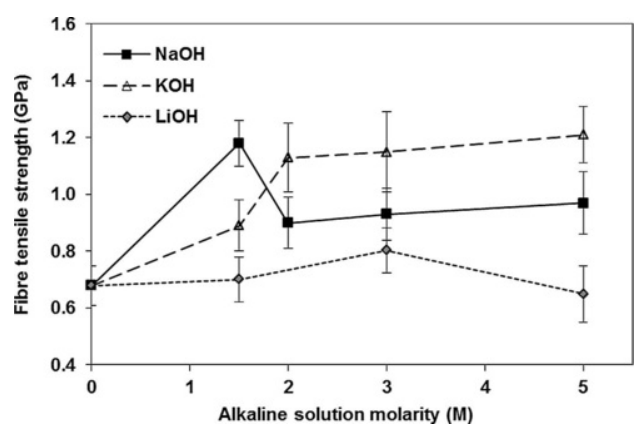

Fig. 1 Average strength of fibres thermally conditioned at $450^{\circ} \mathrm{C}$ and treated in various concentrations of alkaline solutions for $10 \mathrm{~min}$.

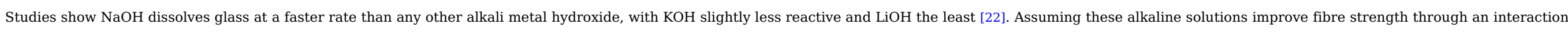

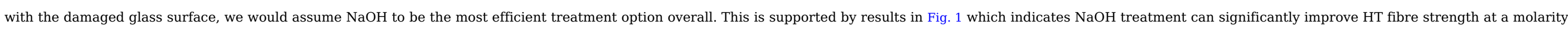

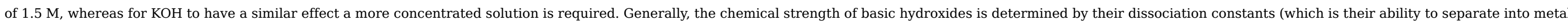

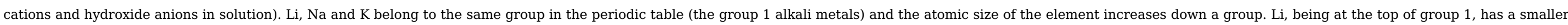

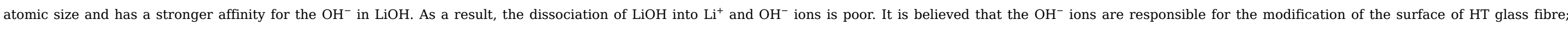

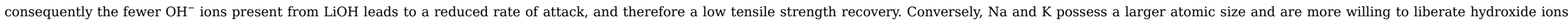

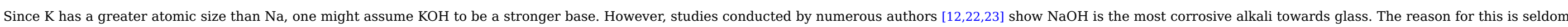

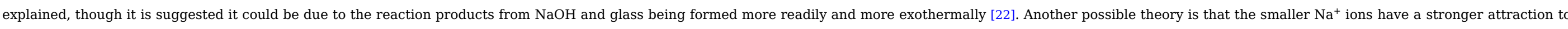

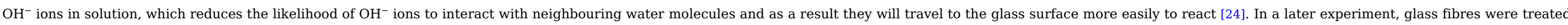

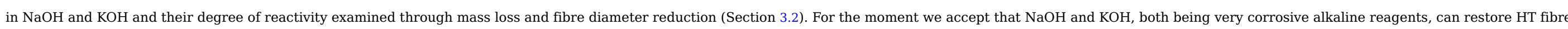
strength through a modification of surface defects. Likewise, poor strength recovery for HT fibres treated in LiOH is attributable to its lower reactivity with glass.

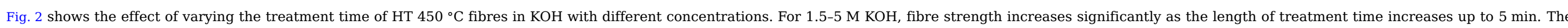

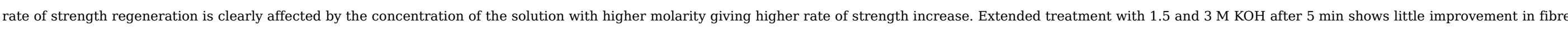

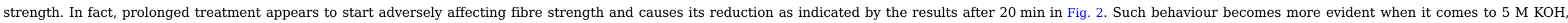
which shows a sharp increase in fibre strength after a short period of $\mathrm{KOH}$ treatment followed by a more significant reverse effect on strength regeneration at an earlier stage compared to $1.5 \mathrm{M}$ and $3 \mathrm{M}$.

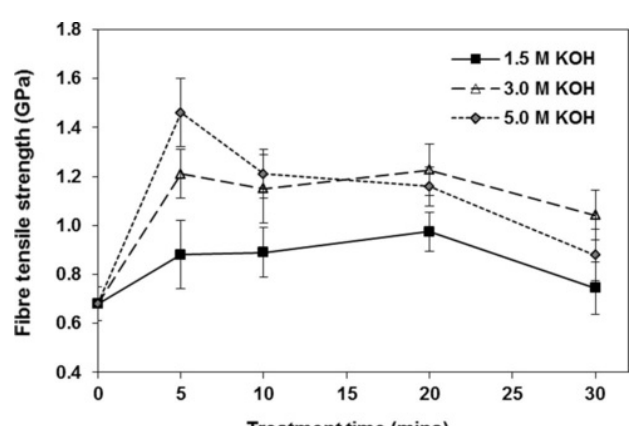

Fig. 2 Average strength of fibres thermally conditioned at $450{ }^{\circ} \mathrm{C}$ and treated in $\mathrm{KOH}$ at different concentrations and times.

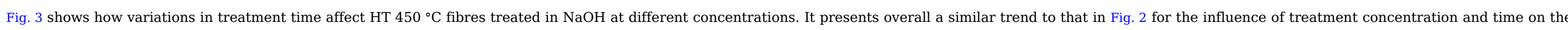

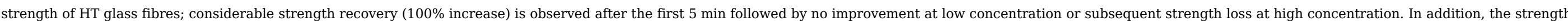




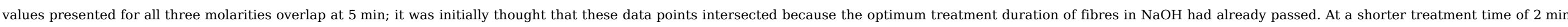

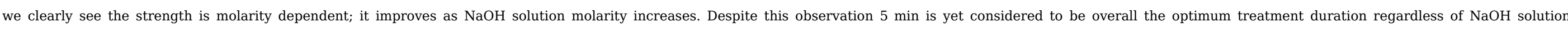

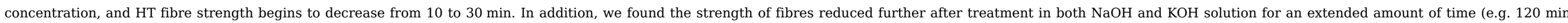
whose data was not presented in Figs. 2 and 3 for clarity).

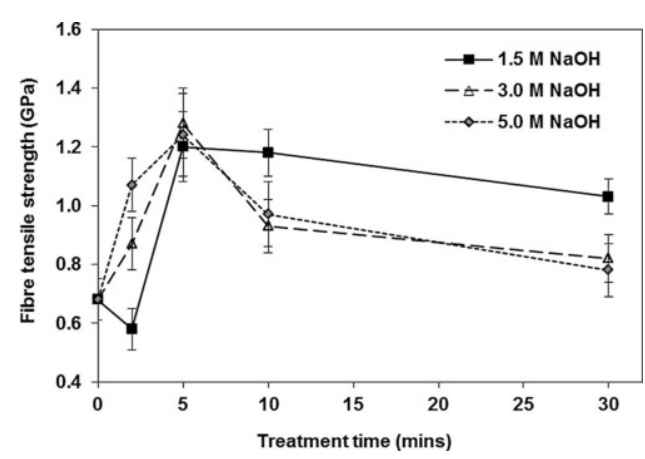

Fig. 3 Average strength of fibres thermally conditioned at $450{ }^{\circ} \mathrm{C}$ and treated in $\mathrm{NaOH}$ at different concentrations and times.

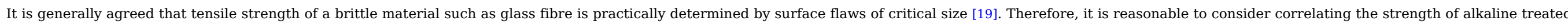

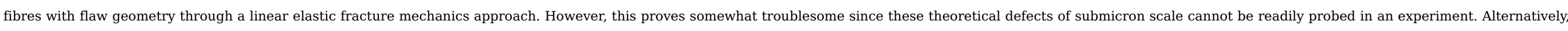

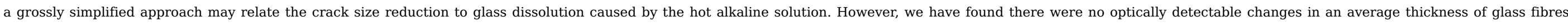

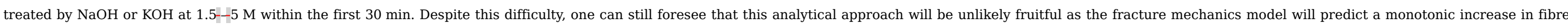

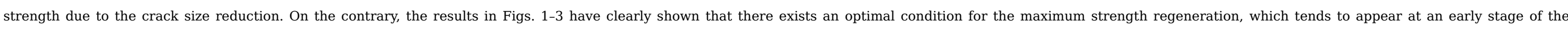

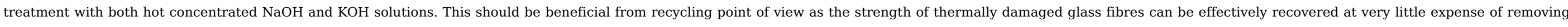
surface materials.

\subsection{Etching effect of alkaline solutions on glass fibre}

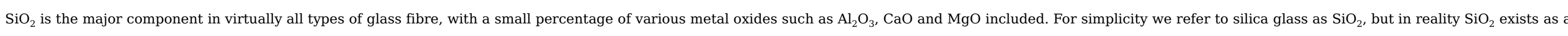

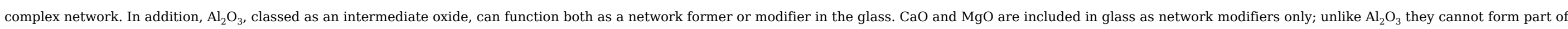
the network structure with $\mathrm{SiO}_{2}$. When glass is in contact with hot, concentrated alkaline solution, the hydroxyl ions attack the $\mathrm{SiO}_{2}$ framework:

["-"Si"-"O"-"Si-] + $\mathrm{OH}^{-} \rightarrow$ ["-"SiO] + + ["-"Si"-"OH]

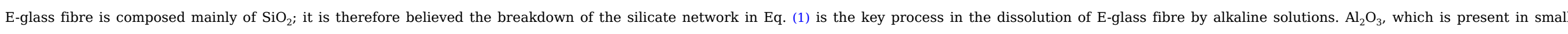

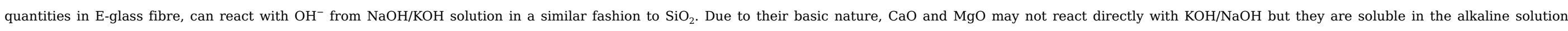

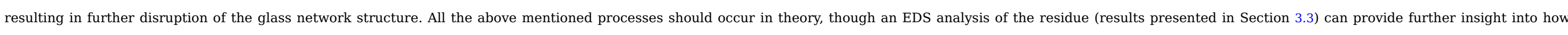

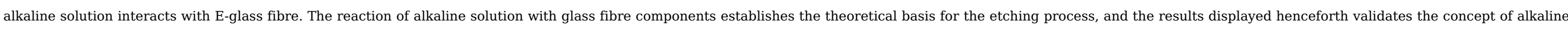
solutions exhibiting an etching effect on E-glass fibre.

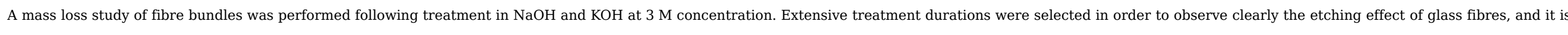

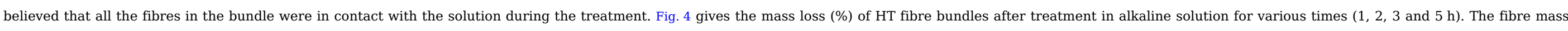

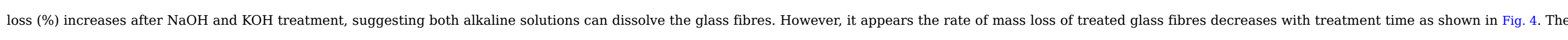

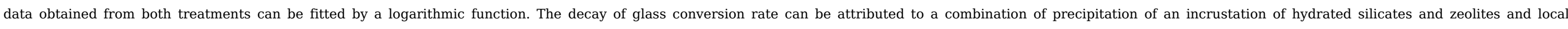




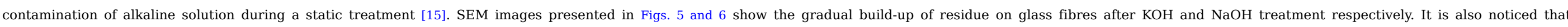

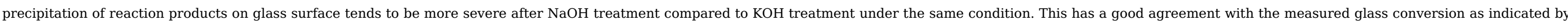
the mass loss in Fig. 4. The results in Figs. 4-6 suggest that $\mathrm{NaOH}$ is more corrosive to glass fibre than $\mathrm{KOH}$ and this agrees well with the studies of silicate bulk glass in [12,22].

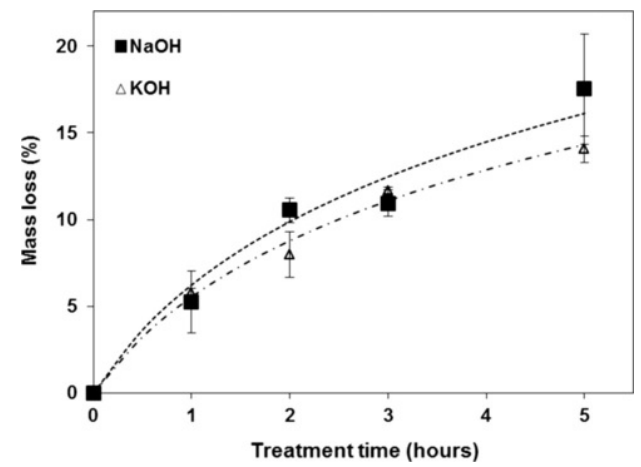

Fig. 4 Mass loss (\%) of glass fibre bundle after treatment in $3 \mathrm{M} \mathrm{NaOH}$ and $\mathrm{KOH}$ at different times.

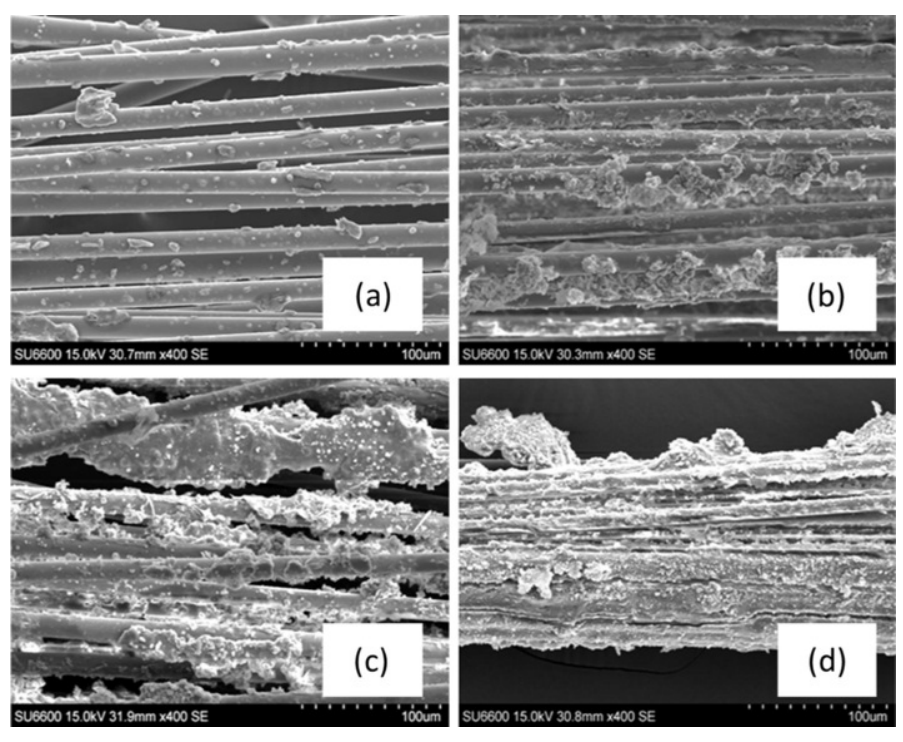

Fig. 5 SEM images of $\mathrm{HT} 450^{\circ} \mathrm{C}$ fibre bundles followed by treatment in $3 \mathrm{M} \mathrm{KOH}$ at (a) $0.5 \mathrm{~h}$, (b) $1 \mathrm{~h}$, (c) $2 \mathrm{~h}$ and (d) $5 \mathrm{~h}$, without rinsing. 


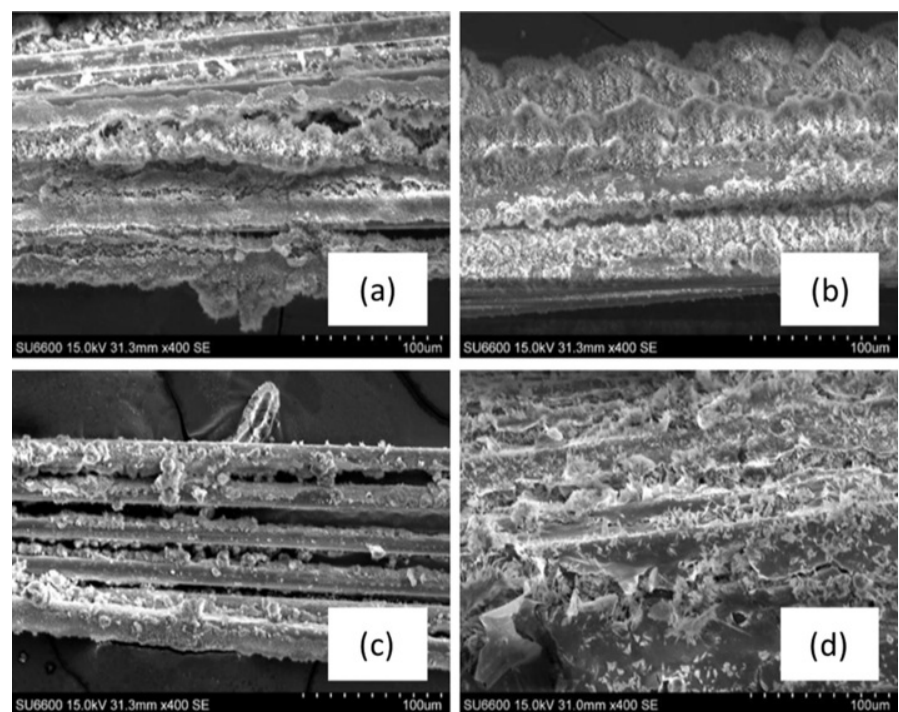

Fig. $6 \mathrm{SEM}$ images of $\mathrm{HT} 450{ }^{\circ} \mathrm{C}$ fibre bundles followed by treatment in $3 \mathrm{M} \mathrm{NaOH}$ at (a) $0.5 \mathrm{~h}$, (b) $1 \mathrm{~h}$, (c) $2 \mathrm{~h}$ and (d) 5 h, without rinsing.

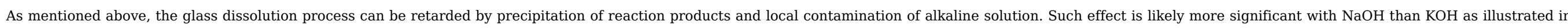

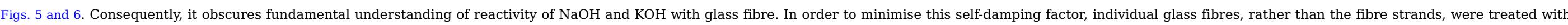

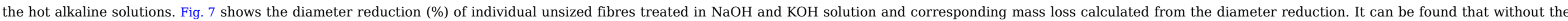

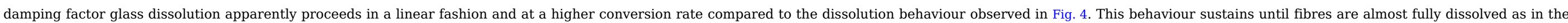

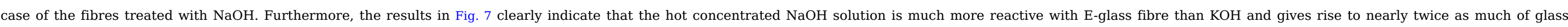
dissolution as that caused by the $\mathrm{KOH}$ solution. The results from Fig. 7 also prove that the method of alkaline treatment to single fibres is a more accurate and effective way of analysing reaction kinetics.

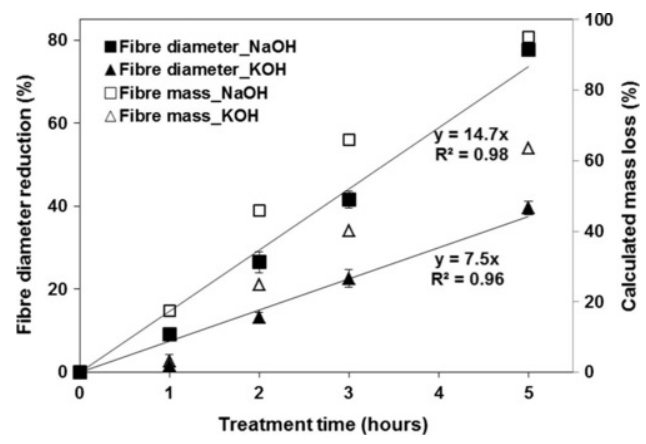

Fig. 7 Fibre diameter reduction (\%) and calculated mass loss of single glass fibre after treatment in $3 \mathrm{M} \mathrm{NaOH}$ and $\mathrm{KOH}$ at different times.

\subsection{Elemental analysis of alkaline treated fibres}

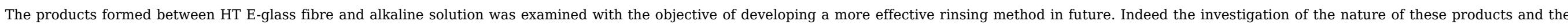

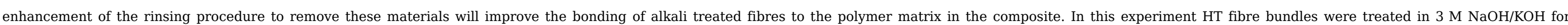

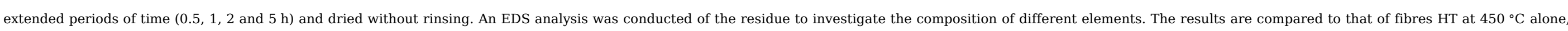

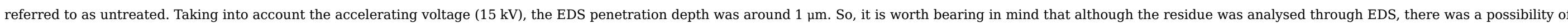




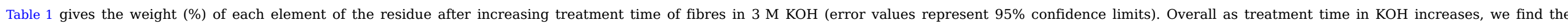

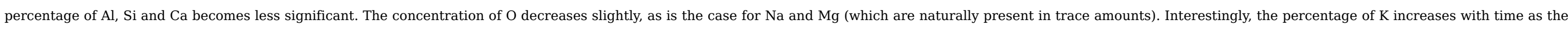

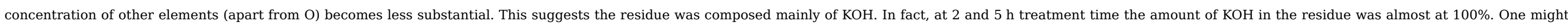

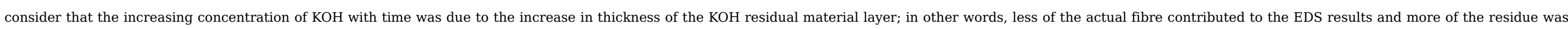
analysed.

Table 1 Weight (\%) of each element present in residue on $3 \mathrm{M} \mathrm{KOH}$ treated fibres at different times, determined by EDS.

\begin{tabular}{|c|c|c|c|c|c|c|c|}
\hline Element & $\mathrm{O}$ & $\mathrm{Na}$ & $\mathrm{Mg}$ & $\mathrm{Al}$ & $\mathrm{Si}$ & $\mathrm{K}$ & $\mathrm{Ca}$ \\
\hline Untreated & $52.2 \pm 1.4$ & $0.5 \pm 0.1$ & $1.6 \pm 0.1$ & $5.9 \pm 0.3$ & $23.9 \pm 2.2$ & $0.1 \pm 0.1$ & $15.3 \pm 1.5$ \\
\hline $0.5 \mathrm{~h}$ & $50.2 \pm 4.2$ & $0.6 \pm 0.1$ & $1.3 \pm 0.1$ & $6.6 \pm 1.2$ & $17.5 \pm 1.8$ & $12.7 \pm 4.5$ & $9.5 \pm 1.0$ \\
\hline $1 \mathrm{~h}$ & $49.8 \pm 2.7$ & $0.1 \pm 0.1$ & $0.9 \pm 0.3$ & $6.3 \pm 2.4$ & $13.2 \pm 3.9$ & $21.2 \pm 8.1$ & $7.9 \pm 2.8$ \\
\hline $2 \mathrm{~h}$ & $42.2 \pm 4.5$ & $0.1 \pm 0.7$ & $0.1 \pm 0.1$ & $5.3 \pm 2.2$ & $2.2 \pm 2.1$ & $48.9 \pm 7.2$ & $0.8 \pm 0.7$ \\
\hline $5 \mathrm{~h}$ & $41.4 \pm 4.1$ & $0.4 \pm 0.2$ & $0.7 \pm 0.5$ & $2.0 \pm 1.0$ & $8.3 \pm 4.1$ & $40.5 \pm 9.8$ & $6.2 \pm 2.9$ \\
\hline
\end{tabular}

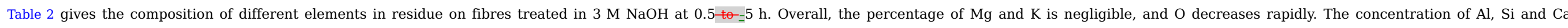

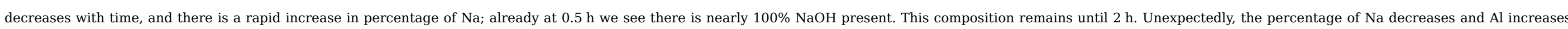

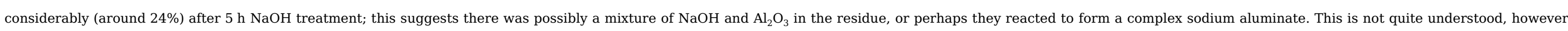
from SEM imaging in Fig. 6 it is clear that a thick film is covering the fibres at $5 \mathrm{~h}$, which could potentially have contributed to the high percentage of Al.

Table 2 Weight (\%) of each element present in residue on $3 \mathrm{M} \mathrm{NaOH}$ treated fibres at different times, determined by EDS.

\begin{tabular}{|c|c|c|c|c|c|c|c|}
\hline Element & $\mathrm{O}$ & $\mathrm{Na}$ & $\mathrm{Mg}$ & $\mathrm{Al}$ & $\mathrm{Si}$ & $\mathrm{K}$ & $\mathrm{Ca}$ \\
\hline Untreated & $52.2 \pm 1.4$ & $0.5 \pm 0.1$ & $1.6 \pm 0.1$ & $5.9 \pm 0.3$ & $23.9 \pm 2.2$ & $0.1 \pm 0.1$ & $15.3 \pm 1.5$ \\
\hline $0.5 \mathrm{~h}$ & $41.2 \pm 3.3$ & $45.5 \pm 11.9$ & - & $1.0 \pm 0.4$ & $3.9 \pm 2.7$ & - & $7.9 \pm 7.5$ \\
\hline $1 \mathrm{~h}$ & $39.6 \pm 1.0$ & $58.1 \pm 1.1$ & - & $0.6 \pm 0.1$ & $1.2 \pm 0.2$ & $0.1 \pm 0.1$ & $0.3 \pm 0.3$ \\
\hline $2 \mathrm{~h}$ & $41.5 \pm 1.6$ & $51.3 \pm 4.7$ & $0.2 \pm 0.2$ & $1.0 \pm 0.6$ & $3.7 \pm 2.3$ & $0.2 \pm 0.2$ & $2.1 \pm 1.0$ \\
\hline $5 \mathrm{~h}$ & $42.0 \pm 2.8$ & $29.3 \pm 9.0$ & - & $24.3 \pm 8.4$ & $2.1 \pm 1.4$ & - & $2.1 \pm 1.5$ \\
\hline
\end{tabular}

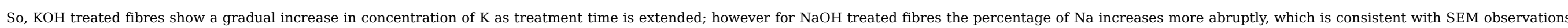

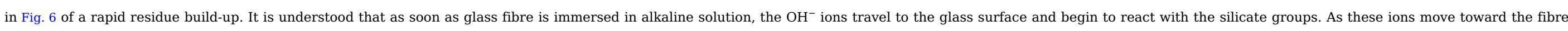

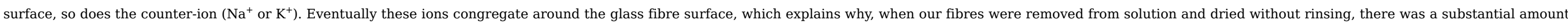

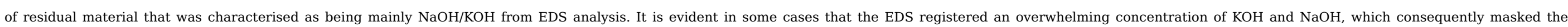

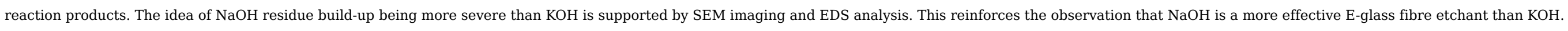

\subsection{Surface roughness and phase imaging of alkaline treated fibres}

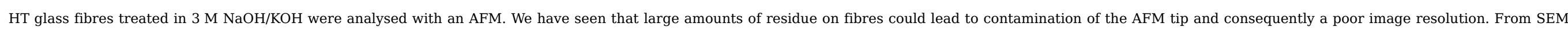




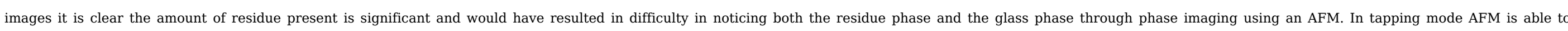

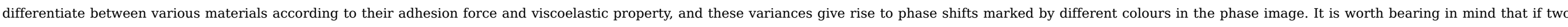

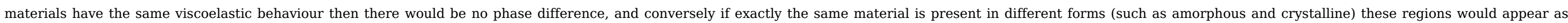
different phases.

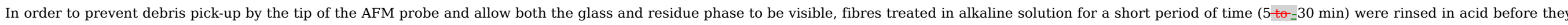

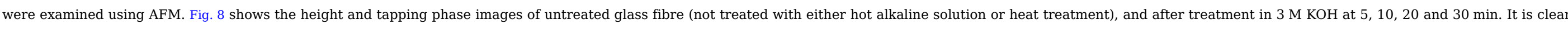

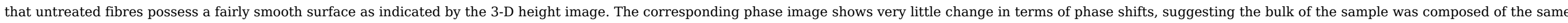

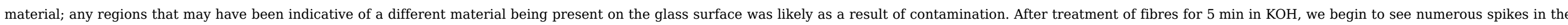

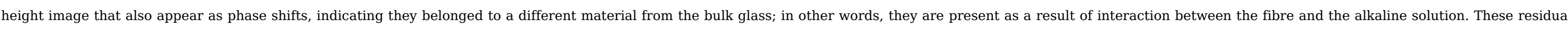

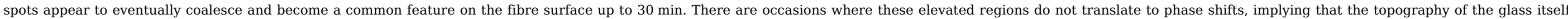
was being affected after alkaline treatment. 

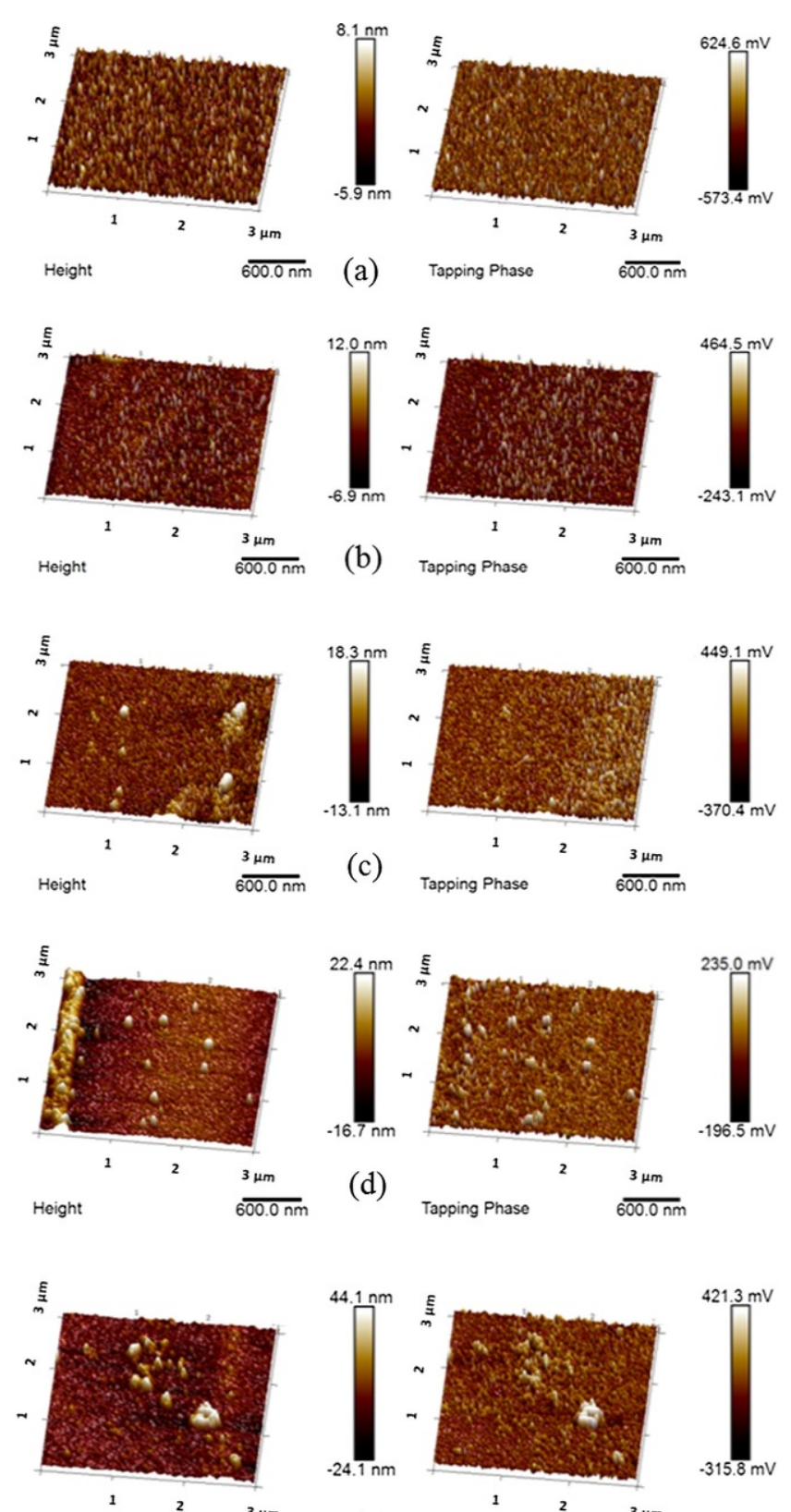

$$
\text { Height } \quad \frac{3 \mu \mathrm{m}}{600.0 \mathrm{~nm}} \text { (e) Tapping Phase } \frac{3 \mu \mathrm{m}}{600.0 \mathrm{~nm}}
$$

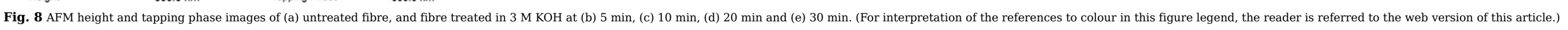

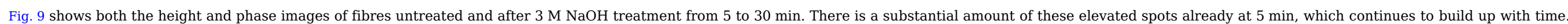

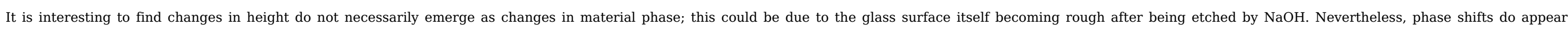



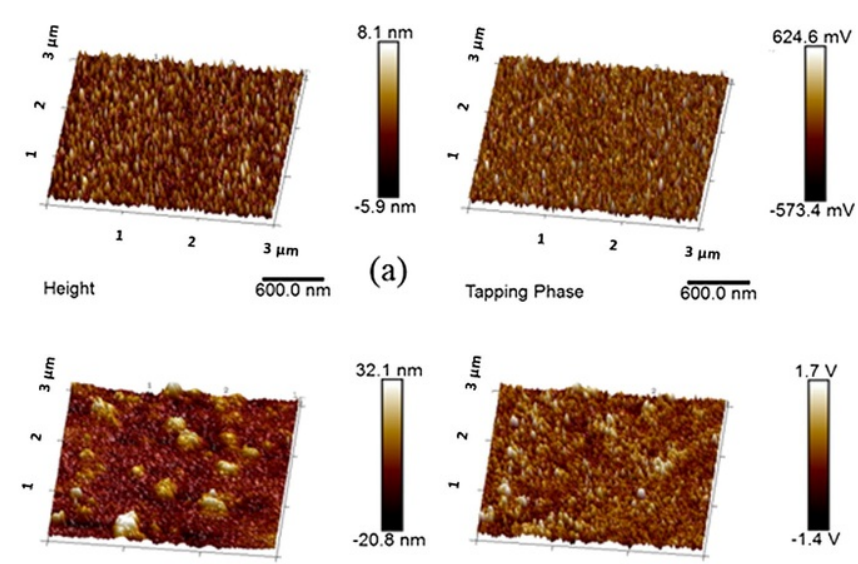

Height

$\frac{3 \mu \mathrm{m}}{600.0 \mathrm{~nm}}$

(b) Tapping Phase $\quad \begin{gathered}1 \\ \frac{3 \mu \mathrm{m}}{600.0 \mathrm{~nm}}\end{gathered}$
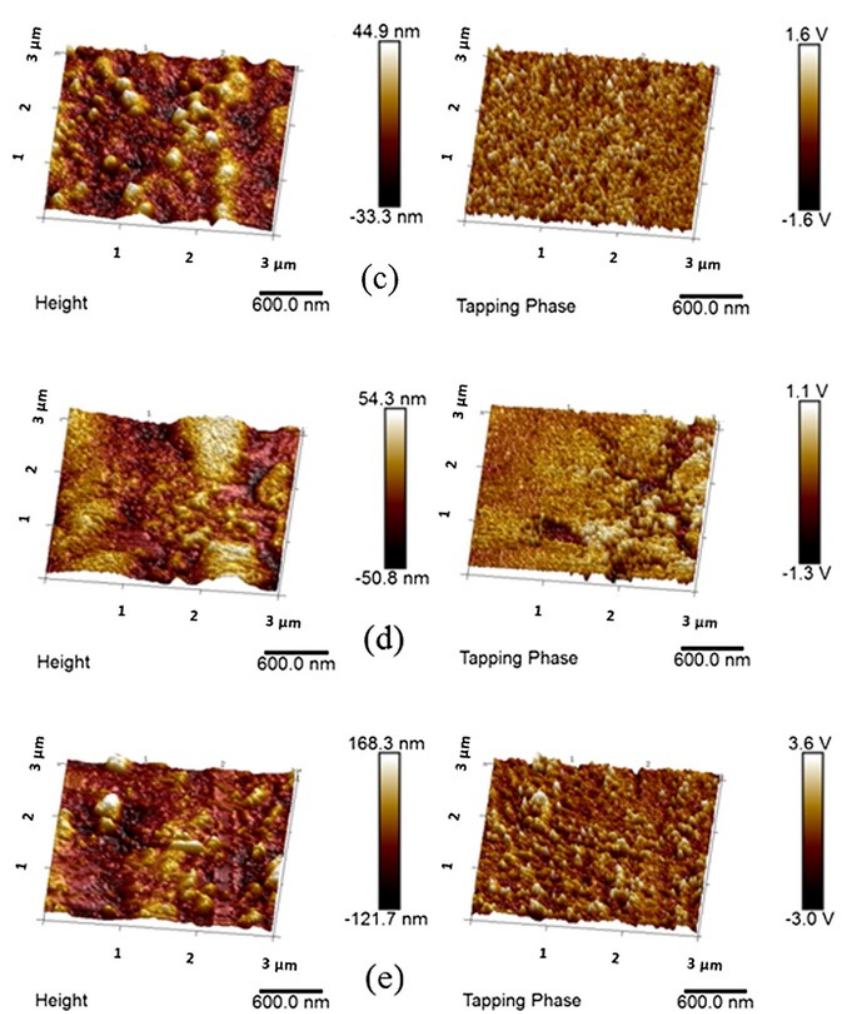


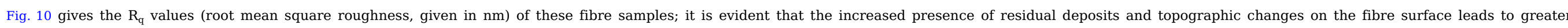

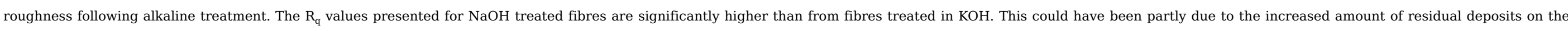

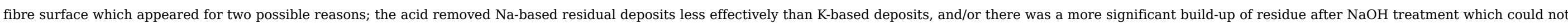

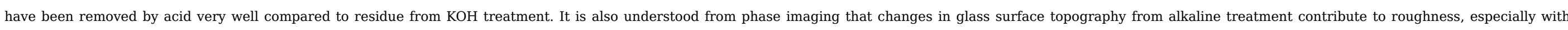
$\mathrm{NaOH}$. We can therefore conclude that AFM supports our previous results from SEM investigations and etching experiments which show NaOH to be more reactive with E-glass than KOH.

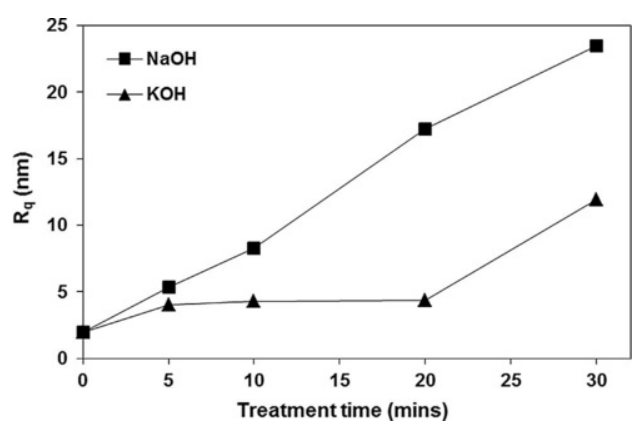

Fig. 10 Roughness $\left(\mathrm{R}_{\mathrm{q}}\right)$ values for

\subsection{FT-IR spectroscopic analysis of alkali treated fibres}

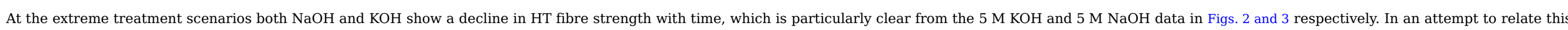

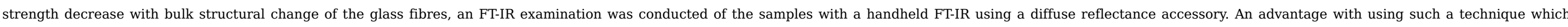

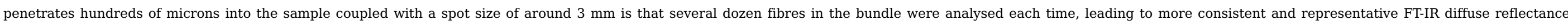

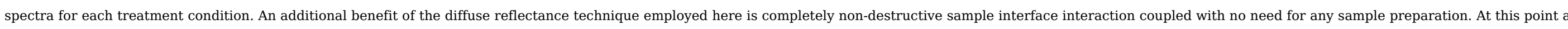

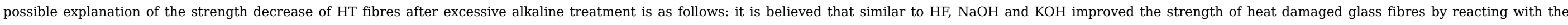

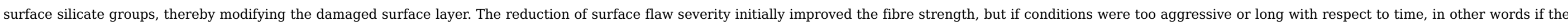

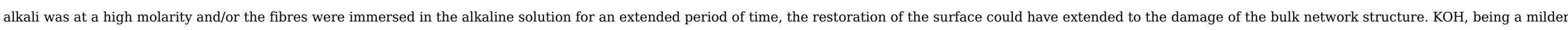

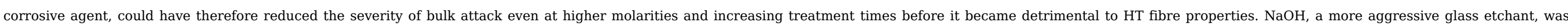

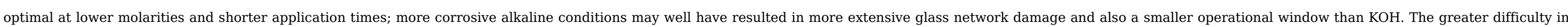
handling residue-coated fibres after prolonged alkaline treatment could also have had a negative effect; the acid rinse was designed to remove most of the residual deposits formed on the surface.

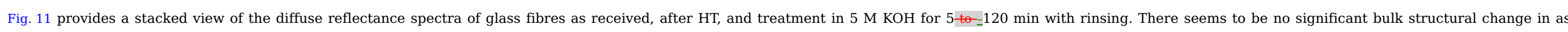

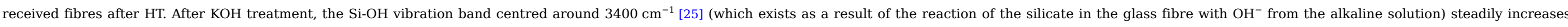

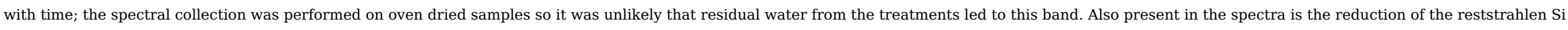
$\mathrm{O}$

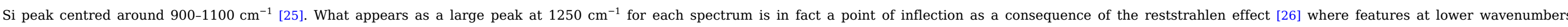
from this point are all negative primarily due to concomitant changes in refractive index with IR absorbance. The initially small peak related to the $\mathrm{Si}$

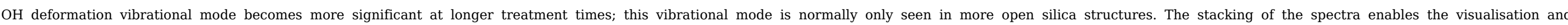

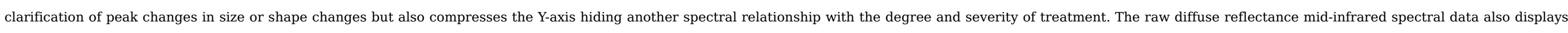
decrease in reflectivity that is directly related to the degree and extent of the $\mathrm{KOH}$ treatment. 


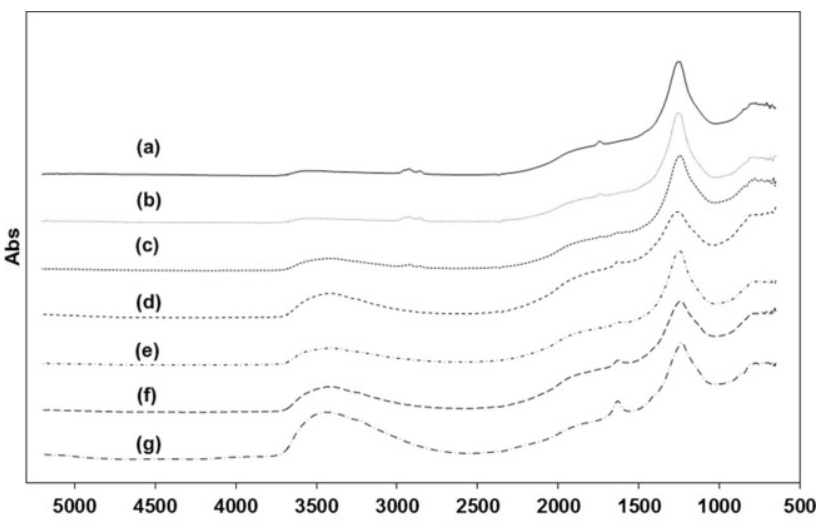

g. 11 stacked

Fig. 11 Stacked view of FT-IR diffuse reflectance spectra of glass fibres (a) as received, (b) after HT, and then treatment in 5 M KOH for (c) 5 min, (d) 10 min, (e) 20 min, (f) 30 min and (g) 120 min, with rinsing.

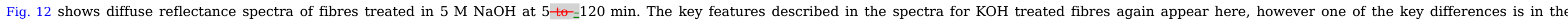

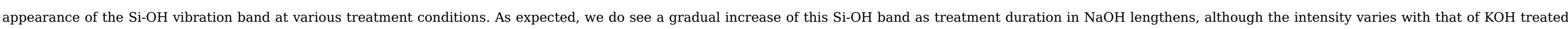
fibres. For example, after 5 min treatment in $\mathrm{NaOH}$ the $\mathrm{Si}$

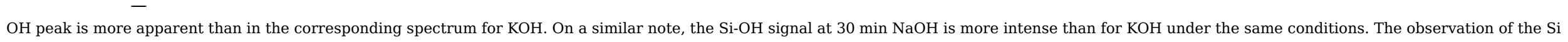

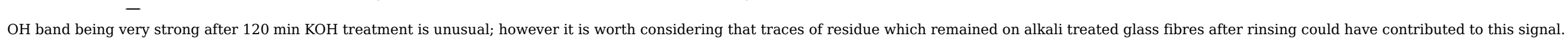

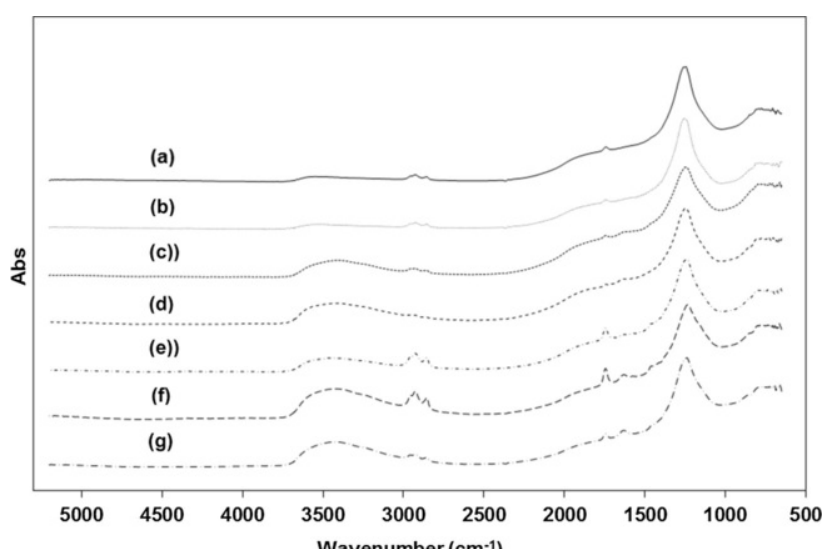

Fig. 12 Stacked view of FT-IR diffuse reflectance spectra of glass fibres (a) as received, (b) after HT, and then treatment in 5 M NaOH for (c) 5 min, (d) 10 min, (e) 20 min, (f) 30 min and (g) 120 min, with rinsing.

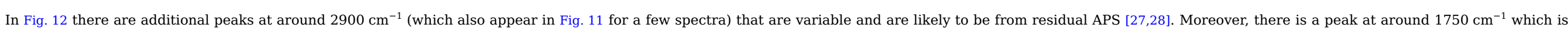
characteristic of a carbonyl (C

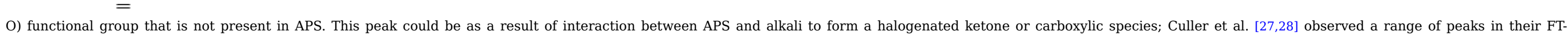

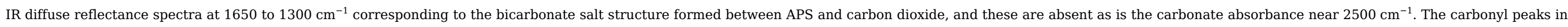
our FT-IR spectra appear at a high wavenumber of $1750 \mathrm{~cm}^{-1}$ which suggests that carboxylic or halogenated ketone groups were present in the fibre samples.

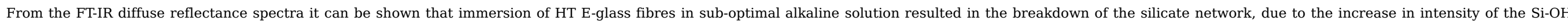




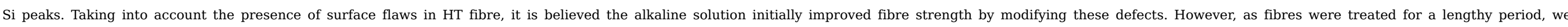

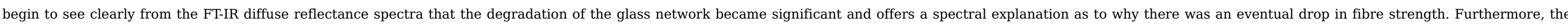

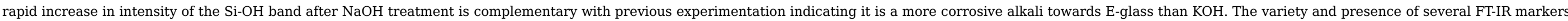
that correlate to the fibre strength offers a possible non-destructive method to pre-validate that the optimal conditions have been applied to the recycled and heat treated glass fibres

\subsection{Fracture surface of alkali treated fibres}

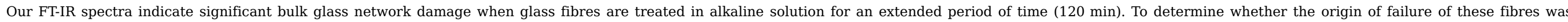

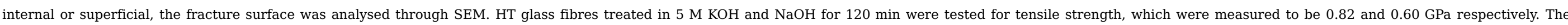
fracture surfaces of some of these fibres were examined under the SEM after tensile testing, with representative images (both for $\mathrm{KOH}$ and $\mathrm{NaOH}$ treated fibres) displayed in Fig. 13.

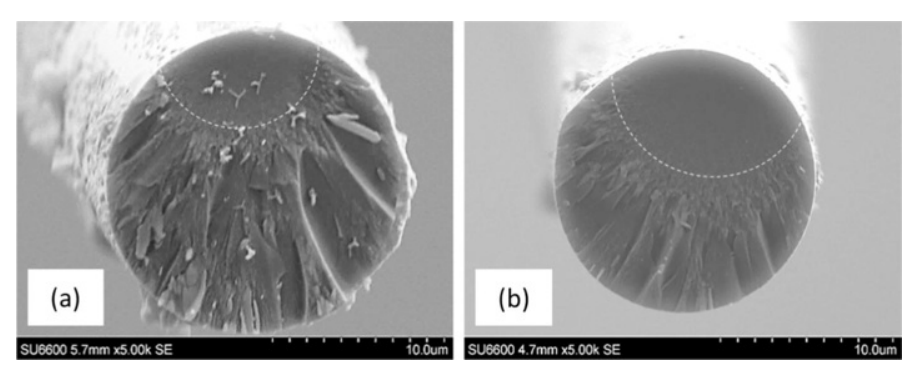

Fig. 13 SEM images of fracture surfaces of fibres $\mathrm{HT}$ and treated in (a) $5 \mathrm{M} \mathrm{KOH}$ for $120 \mathrm{~min}$ and (b) $5 \mathrm{M} \mathrm{NaOH}$ for $120 \mathrm{~min}$.

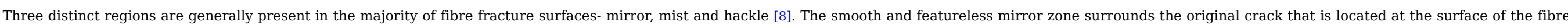

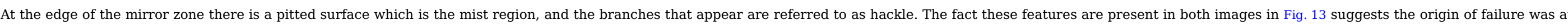

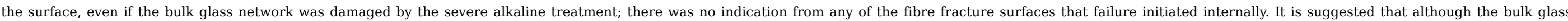

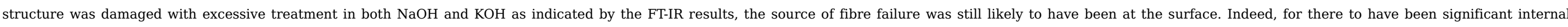
damage the glass fibre surface would have had to react first with the alkaline solution and consequently remain the weakest region.

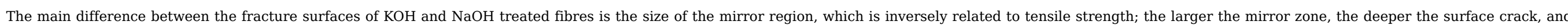

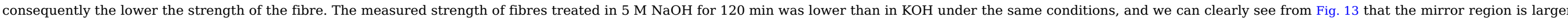
for $\mathrm{NaOH}$ treated fibre.

\section{Conclusions}

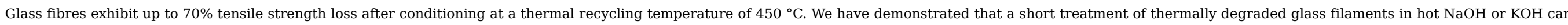

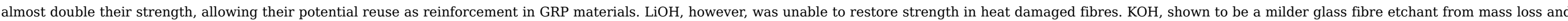

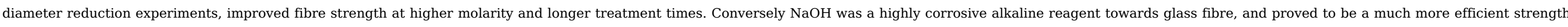

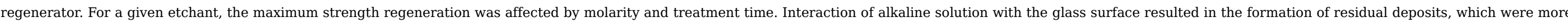

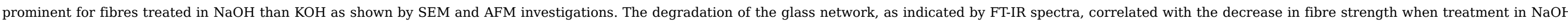

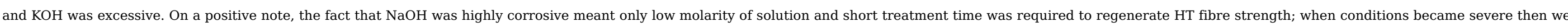

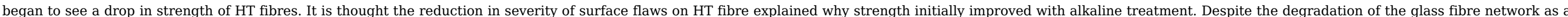




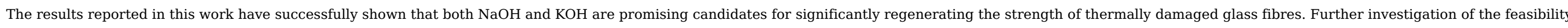

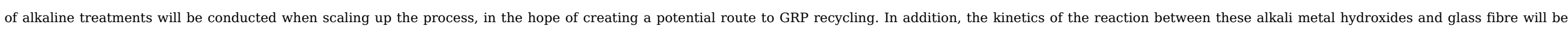
studied in more detail to help us further understand the etching mechanism.

\section{Acknowledgements}

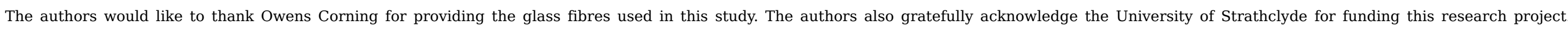

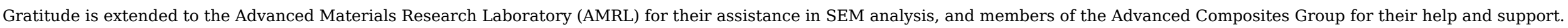

\section{References}

[1] Job S, Leeke G, Mativenga PT, Oliveux G, Pickering S, Shuaib NA. Composites recycling: Where are we now? Report for Composites UK Ltd; July 2016. Available at

<https://compositesuk.co.uk/system/files/documents/Recycling\%20Report\%202016.pdf>.

[2] S. Job, Recycling glass fibre reinforced composites - history and progress, Reinforced Plast 57 (5), 2013, 19-23.

[3] Albers H, Greiner S, Seifertand H, Kühne U. Recycling of wind turbine rotor blades - fact or fiction? DEWI Mag 2009:32-38.

[4] G. Oliveux, L. Dandy and G. Leeke, Current status of recycling of fibre reinforced polymers: review of technologies, reuse and resulting properties, Prog Mater Sci 72, 2015, 61-99.

[5] S.J. Pickering, Recycling technologies for thermoset composite materials- current status, Compos A: Appl Sci Manuf 37, 2006, 1206-1215.

[6] J.L. Thomason, L. Yang and R. Meier, The properties of glass fibres after conditioning at composite recycling temperatures, Compos A Appl Sci Manuf $\mathbf{6 1}$, 2014, 201-208.

[7] P.G. Jenkins, L. Yang, J.J. Liggat and J.L. Thomason, Investigation of the strength loss of glass fibre after thermal conditioning, J Mater Sci 50, 2015 , $1050-1057$.

[8] S. Feih, E. Boiocchi, G. Mathys, A.G. Gibson and A.P. Mouritz, Mechanical properties of thermally-treated and recycled glass fibres, Compos B Eng 42 (3), 2011 , 350-358.

[9] U. Nagel, L. Yang, C.C. Kao and J.L. Thomason, Effects of thermal recycling temperatures on the reinforcement potential of glass fibers, Polym Compos 2016.

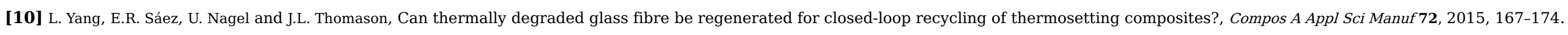

[11] G.A.C.M. Spierings, Wet chemical etching of silicate glasses in hydrofluoric acid based solutions, J Mater Sci 28 (23), 1993, 6261-6273.

[12] S. Kouassi, J. Andji, J. Bonnet and S. Rossignol, Dissolution of waste glasses in high alkaline solutions, Ceramics - Silikáty 54 (3), 2010, 235-240.

[13] R. Smith and P. Corbin, Attack of glasses by alkaline solutions, J Am Ceram Soc 32 (6), 1949, 195-198.

[14] V.S. Molchanov and N.E. Prikhidko, Corrosion of silicate glasses by alkaline solutions, Bull Acad SCi USSR, Div Chem SCi 6, 1995, $1179-1184$.

[15] B. Wei, H. Cao and S. Song, Tensile behavior contrast of basalt and glass fibers after chemical treatment, Mater Des 31, 2010, $4244-4250$.

[16] S. Feih, K. Manatpon, Z. Mathys, A. Gibson and A. Mouritz, Strength degradation of glass fibers at high temperatures, J Mater Sci 44 (2), $2008,392-400$.

[17] P.G. Jenkins, Understanding physical changes and strength loss of E-glass fibres following exposure to elevated temperatures, Mater Sci Technol 2016.

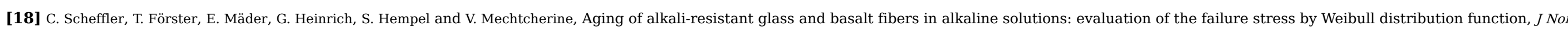
Cryst Solids 355 (52-54), 2009, 2588-2595.

[19] J. Thomason, U. Nagel, L. Yang and E. Sáez, Regenerating the strength of thermally recycled glass fibres using hot sodium hydroxide, Compos A Appl Sci Manuf 87, 2016, 220-227.

[20] E. Sáez, Regenerating the strength of thermally recycled glass fibres using chemical treatments, PhD Thesis2016, University of Strathclyde. 
[21] L. Yang and J.L. Thomason, Effect of silane coupling agent on mechanical performance of glass fibre, J Mater Sci 48, $2013,1947-1954$.

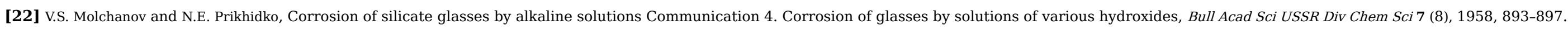

[23] J. Hooley, The kinetics of the reaction of silica with group I hydroxides, Can J Chem 39 (6), 1961, 1221-1230.

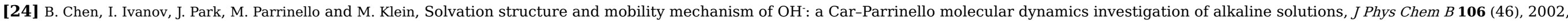
12006-12016.

[25] H. Ishida and J. Koenig, Fourier transform infrared spectroscopic study of the silane coupling agent/porous silica interface, J Colloid Interface Sci 64 (3), 1978, 555-564.

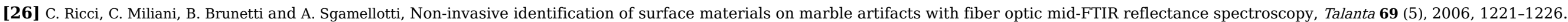

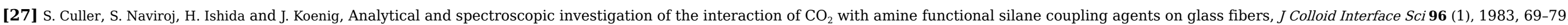

[28] S. Culler, H. Ishida and J. Koenig, The silane interphase of composites: effects of process conditions on $\gamma$-aminopropyltriethoxysilane, Polym Compos 7 (4), $1986,231-238$.

\section{Queries and Answers}

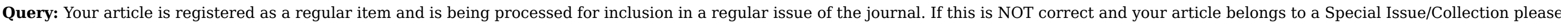
contact v.g@elsevier.com immediately prior to returning your corrections.

Answer: Ok

Query: The author names have been tagged as given names and surnames (surnames are highlighted in teal color). Please confirm if they have been identified correctly. Answer: Correct 